See discussions, stats, and author profiles for this publication at: https://www.researchgate.net/publication/335572315

\title{
HIERARCHICAL CLASSIFICATION OF BRAZILIAN SAVANNA PHYSIOGNOMIES USING VERY HIGH SPATIAL RESOLUTION IMAGE, SUPERPIXEL AND GEOBIA
}

Preprint · August 2019

CITATIONS

0

5 authors, including:

Alana Kasahara Neves

National Institute for Space Research, Brazil

11 PUBLICATIONS 4 CITATIONS

SEE PROFILE

Cesare Di Girolamo Neto

National Institute for Space Research, Brazil

28 PUBLICATIONS 19 CITATIONS

SEE PROFILE
READS

81

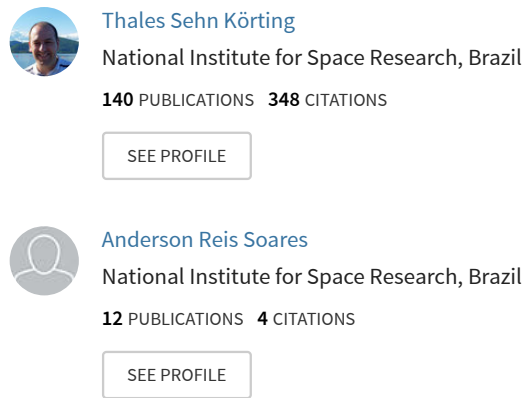

Some of the authors of this publication are also working on these related projects:

Management of metadata from remote sensing big data (FAPESP 2017/24086-2) View project

GeoDMA - Geographic Data Mining Analyst View project 


\title{
HIERARCHICAL CLASSIFICATION OF BRAZILIAN SAVANNA PHYSIOGNOMIES USING VERY HIGH SPATIAL RESOLUTION IMAGE, SUPERPIXEL AND GEOBIA
}

\author{
Alana Kasahara Neves, Thales Sehn Körting, Cesare Di Girolamo Neto, \\ Anderson Reis Soares and Leila Maria Garcia Fonseca \\ Image Processing Division (DPI) - National Institute for Space Research (INPE) \\ Av. dos Astronautas, 1758, São José dos Campos - SP, Brazil
}

\begin{abstract}
An accurate mapping of Brazilian Savanna (Cerrado) is still a difficult task due to the high spatial variability and spectral similarity between its vegetation types, called physiognomies. This work proposes a methodology based on the hierarchy of physiognomies, GEOBIA techniques with Superpixel and a very high spatial resolution image (WorldView2) to classify the Cerrado physiognomies in an area of preserved vegetation. Seven classes were distinguished: Gallery Forest, Wooded Savanna, Typical Savanna, Shrub Savanna, Shrub Grassland, Open Grassland and Rocky Grassland. The texture features were essential for the classification and the hierarchical approach obtained higher accuracies than the nonhierarchical approach. Moreover, GEOBIA and Superpixel were essential to represent the context that characterizes each physiognomy.
\end{abstract}

Index Terms - Cerrado, Random Forest, context

\section{INTRODUCTION}

The Brazilian Savanna, known as Cerrado, is the second largest Brazilian biome, occupying an area of $24 \%$ of the Brazilian territory. Cerrado is considered one of the 35 hotspots for biodiversity conservation on a global scale [1]. It has a flora containing more than 12 thousand species, of which $40 \%$ are endemic. An accurate mapping of Cerrado vegetation is an essential task for assessing biodiversity and improving estimation of Carbon storage in this biome.

Large-scale mapping of the Cerrado vegetation using remote sensing images is still a challenge, due to the high spatial variability and spectral similarity between its vegetation types, called physiognomies. According to the classification legend proposed by [2], there are 25 physiognomies. They vary in structure, density and biomass and can be grouped

The authors thank the Brazilian National Research Council (CNPq) (grant № 140372/2017-2) and the São Paulo Research Foudation (FAPESP, grant no 2017/24086-2) for the financial support and also the DigitalGlobe Foundation for supplying the image for this study and cooperating with students at INPE. into three major natural formations: Grasslands, Savannas and Forests.

Therefore, physiognomies can be distinguished hierarchically: the identification of the major natural formation in a first level of classification can improve the identification of more detailed physiognomies (e.g. Shrub Savanna and Shrub Grassland). Nevertheless, the hierarchical structure of this legend is not being explored in remote sensing approaches ([3], [4]).

The legend [2] was created based on in situ observations, so the identification of each physiognomy relies on a context based on aspects like proximity of water bodies and presence of certain vegetation species or rocky outcrops. Thus, a per pixel classification would not be enough to correctly identify the physiognomies.

In order to consider the context and the hierarchical structure in a classification process, GEOBIA (Geographic Objectbased Image Analysis) techniques are a useful tool, once they are based on segmentation and feature extraction [5]. One approach of image segmentation, Superpixel [6], is becoming very popular because of its simplicity and computational efficiency. It isolates spectrally homogeneous regions creating meaningful objects of similar sizes. Superpixel has never been tested in applications related to Cerrado physiognomies classification.

In this context, this work aims to develop a semi-automatic hierarchical classification procedure for mapping Brazilian Savanna physiognomies, using GEOBIA with Superpixel segmentation. Several datasets containing different features were tested and the hierarchical approach was compared with a non-hierarchical one.

\section{METHODOLOGY}

\subsection{Study area}

The study area is in the Brasília National Park (BNP) in Federal District - Brazil, which has approximately 30,000 hectares of preserved Cerrado vegetation. The physiognomies found on this area are Gallery Forest (Mata de Galeria), Wooded Savanna (Cerrado Denso), Typical Savanna 
Table 1. Description of physiognomies at two levels.

\begin{tabular}{|c|c|c|}
\hline & & First Level \\
\hline 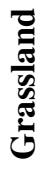 & \multicolumn{2}{|c|}{ Herbaceous vegetation with or without shrubs } \\
\hline 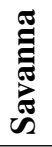 & \multicolumn{2}{|c|}{$\begin{array}{l}\text { Trees scattered over shrubs and herbaceous layers, } \\
\text { no continuous canopies }\end{array}$} \\
\hline 焉 & \multicolumn{2}{|c|}{$\begin{array}{l}\text { Arboreal species forming continuous } \\
\text { or discontinuous canopies }\end{array}$} \\
\hline \multicolumn{3}{|r|}{ Second Level } \\
\hline \multirow{3}{*}{ 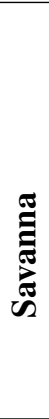 } & $\begin{array}{l}\text { Wooded } \\
\text { Savanna }\end{array}$ & $\begin{array}{l}\text { Predominantly arboreal vegetation. } \\
\text { Tree cover between } 50 \% \text { and } 70 \% \\
\text { and tree height of } 5 \text { up to } 8 \mathrm{~m}\end{array}$ \\
\hline & $\begin{array}{l}\text { Typical } \\
\text { Savanna }\end{array}$ & $\begin{array}{l}\text { Predominantly } \\
\text { arboreal-shrub vegetation. } \\
\text { Tree cover between } 20 \% \text { and } 50 \% \\
\text { and tree height of } 3 \text { up to } 6 \mathrm{~m}\end{array}$ \\
\hline & $\begin{array}{l}\text { Shrub } \\
\text { Savanna }\end{array}$ & $\begin{array}{l}\text { Arboreal-shrub vegetation. } \\
\text { Tree cover between } 5 \% \text { and } 20 \% \\
\text { and tree height of } 2 \text { up to } 3 \mathrm{~m}\end{array}$ \\
\hline \multirow{3}{*}{$\frac{\vec{E}}{\frac{\pi}{\tilde{v}}}$} & $\begin{array}{c}\text { Shrub } \\
\text { Grassland }\end{array}$ & $\begin{array}{l}\text { Herbaceous-shrub vegetation } \\
\text { and some isolated trees }\end{array}$ \\
\hline & $\begin{array}{c}\text { Open } \\
\text { Grassland }\end{array}$ & Predominantly herbaceous vegetation \\
\hline & $\begin{array}{c}\text { Rocky } \\
\text { Grassland }\end{array}$ & $\begin{array}{l}\text { Herbaceous-shrub vegetation } \\
\text { and presence of rocky outcrop }\end{array}$ \\
\hline
\end{tabular}

(Cerrado Típico), Shrub Savanna (Cerrado Ralo), Shrub Grassland (Campo Sujo), Open Grassland (Campo Limpo) and Rocky Grassland (Campo Rupestre) (Table 1). The BNP is an important protected area for the Cerrado biome once it contains several endangered species (e.g. Jaguar - Panthera onca and Anteater - Myrmecophaga tridactyla) and also contains a dam that is responsible for $25 \%$ of the Federal District's water supply.

\subsection{Very high spatial resolution image and preprocessing}

A WorldView-2 image (tile ID 103001003373A600) acquired in July 22, 2014 with a spatial resolution of 2 meters was used. This image has 8 spectral bands, of which 7 were used in this work: Blue (450-510nm), Green (510-580nm), Yellow (585$625 \mathrm{~nm})$, Red (630-690nm), Red-Edge (705-745nm), Near Infrared 1 (NIR-1 - 770-895nm) and Near Infrared 2 (NIR2 860- 1040nm).

The image was converted from Digital Numbers (DNs) to surface reflectance using the Fast Line-of-sight Atmospheric Analysis of Hypercubes (FLAASH) algorithm [7] on the ENVI 5.2 software. Also a mask was created to remove con- structed areas, water bodies, bare soil and burned areas from the analysis. The mask was identified as "Non Observed" in the final classification legend.

\subsection{Superpixel}

The Superpixel approach is a region-based image segmentation that over-segment the image to produce meaningful objects (Superpixels) [6]. According to [8], the Superpixels should adhere well to image boundaries and the algorithm should be memory efficient, simple to use, increase the speed and improve the quality of results.

The Superpixel algorithm used in this paper was the Simple Linear Iterative Clustering (SLIC). This is an adaptation of k-means algorithm [9], that computes the weighted distance measure through a combination of colour, in the CIELAB colour space, and spatial proximity.

The algorithm creates a regularly spaced grid controlled by the number of desired Superpixels. After that, each pixel overlapped by the search region is associated with the nearest cluster centre, then the cluster centres are adjusted on an update step and this procedure is repeated until convergence.

It is also possible to control the compactness of the Superpixels. If the compactness value is large, spatial proximity is more relevant, therefore Superpixels are more compact (close to a square shape). However, when the compactness is small, they adhere more to image boundaries and have less regular size and shape [8]. In this work, compactness equal to 850 was used.

\subsection{Feature extraction}

In order to obtain object-based information, features were extracted combining the Superpixels and the WorldView-2 image. First, the features were generated for each image pixel using the surface reflectance values. Then, the average values for each feature on each Superpixel was calculated, except the texture features, that were performed according to [10].

The dataset is composed by the following features:

- Spectral: Surface reflectance from the 7 WorldView-2 bands used;

- TC: Tasseled Cap Transformation - Greenness, Wetness and Brightness components [11];

- SMA: Spectral Mixture Analysis - Soil, Shadow and Vegetation fractions [12];

- VI: Vegetation Indices - Normalized Difference Vegetation Index (NDVI), Enhanced Vegetation Index (EVI), Enhanced Vegetation Index 2 (EVI2), Soil-Adjusted Vegetation Index (SAVI) and Modified Soil-Adjusted Vegetation Index 2 (MSAVI2) - all of them described in [4];

- TX: Gray Level Co-occurrence Matrix (GLCM) Texture - Contrast, Dissimilarity, Entropy, Homogeneity, Correlation and Second Angular Moment [10]. 


\subsection{Classification}

The algorithm used to perform the classification was Random Forest [13]. The number of trees on each forest was set to 100. The classification was generated using a 10 -fold cross validation method. The overall accuracy and the accuracy for each class, derived from the confusion matrix, were used.

In the hierarchical approach, a first experiment was performed using all features (TC + SMA + VI + Spectral + TX). Then several experiments were performed using all features except one at a time. Thus, this procedure can outline the importance of each group of features for the classification.

The result of the First Level of the classification was used as input data to the next level. The misclassified Superpixels at the First Level were also considered as errors at the Second Level. In the non-hierarchical approach, the classification was performed in only one step with seven possible classes.

\subsection{Fieldwork and validation}

The classification was validated by a fieldwork that occurred in July, 2017, in which 141 sample points were collected [4]. More 888 sample points were visually interpreted using the WorldView-2 image, generating a total of 1029 validation points.

\section{RESULTS}

The Overall Accuracies (OA) of each experiment for both hierarchical classification levels are presented in Table 2. On the First Level (distinguished Forest, Savanna and Grassland), the highest OA was of $88.21 \%$. It was obtained considering all features except the VI. The removal of TC, SMA and Spectral features also provided close OA values, ranging from $87.62 \%$ to $87.92 \%$. On the other hand, when TX features were not used, the OA dropped to $85,17 \%$, indicating that they play an important role in the classification of Cerrado physiognomies.

The Second Level of hierarchical classification is composed by Savanna and Grassland. The first one was subdivided into the physiognomies of Wooded Savanna, Typical Savanna and Shrub Savanna, while the second one was distinguished into Shrub Grassland, Open Grassland and Rocky Grassland physiognomies. Forest is not included on the Second Level, once the study area has only one Forest physiognomy (Gallery Forest), that was already distinguished on the First Level.

For the Savanna physiognomies classification, the highest OA (67.33\%) was also obtained using all the features except the VI. The largest drop in the OA happened when TX features were excluded from the dataset $(62.33 \%)$. The use of TX features proved to be essential for discriminating these classes, once they are capable of capturing the alternation between trees and shrub vegetation [4].
Table 2. Overall accuracy (\%) for each level of hierarchical classification.

\begin{tabular}{|c|c|c|c|c|}
\hline \multirow{2}{*}{\multicolumn{2}{|c|}{ 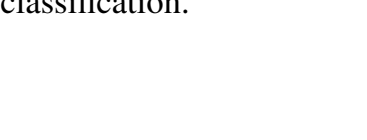 }} & \multirow{2}{*}{$\begin{array}{l}\text { First } \\
\text { Level }\end{array}$} & \multicolumn{2}{|c|}{$\begin{array}{l}\text { Second } \\
\text { Level }\end{array}$} \\
\hline & & & Savanna & Grassland \\
\hline \multirow{6}{*}{ } & $\begin{array}{c}\text { TC + SMA + } \\
\text { VI + Spectral + TX }\end{array}$ & 87.72 & 65.67 & 64.78 \\
\hline & All - TC & 87.62 & 65.17 & 64.18 \\
\hline & All - SMA & 87.82 & 66.83 & 64.48 \\
\hline & All - VI & 88.21 & 67.33 & 62.39 \\
\hline & All - Spectral & 87.92 & 66.00 & 63.58 \\
\hline & All - TX & 85.17 & 62.33 & 62.69 \\
\hline
\end{tabular}

Table 3. Accuracy (\%) for each physiognomy.

\begin{tabular}{|c|c|c|}
\hline Physiognomy & Hierarchical & Non-hierarchical \\
\hline Gallery Forest & 95.51 & 96.63 \\
\hline Wooded Savanna & 19.57 & 15.22 \\
\hline Typical Savanna & 88.95 & 87.29 \\
\hline Shrub Savanna & 39.25 & 36.56 \\
\hline Shrub Grassland & 72.51 & 69.67 \\
\hline Open Grassland & 55.36 & 50.89 \\
\hline Rocky Grassland & 16.67 & 8.33 \\
\hline Overall Accuracy & 68.95 & 66.40 \\
\hline
\end{tabular}

For the classification of Grassland physiognomies, the highest OA (64.78\%) was obtained when using all features. The removal of the VI from the dataset dropped the OA to the lowest value $(62.39 \%)$. Differently from what happened to the First Level and the discrimination of Savanna physiognomies, the VI were essential to improve the classification of Grassland physiognomies, once higher values of VI were noticed for the Shrub Grasslands when compared to the Open grasslands and Rocky Grasslands.

The comparison between hierarchical and non-hierarchical OA classification for each class is presented in Table 3. The Gallery Forest was the only class that had a slightly better accuracy using the non-hierarchical approach. However, the presence of a unique Forest class on the study site hinders the evaluation of the hierarchy for the classification of Forest physiognomies.

The remaining six classes had higher accuracies on the hierarchical approach, indicating that the inclusion of the hierarchical aspect in the classification of the Cerrado physiognomies can improve the classification of this vegetation. The hierarchical OA (68.95\%) includes the correctly classified Superpixels of Forest, Savanna and Grassland physiognomies and was also higher than the non-hierarchical OA (66.40\%).

The classification result, using the Random Forest models with highest OA (Table 2), are presented in Figure 1. The vegetation map shows a consistent result, with correct transitions between the studied physiognomies.

The accuracies obtained in this work can be compared 


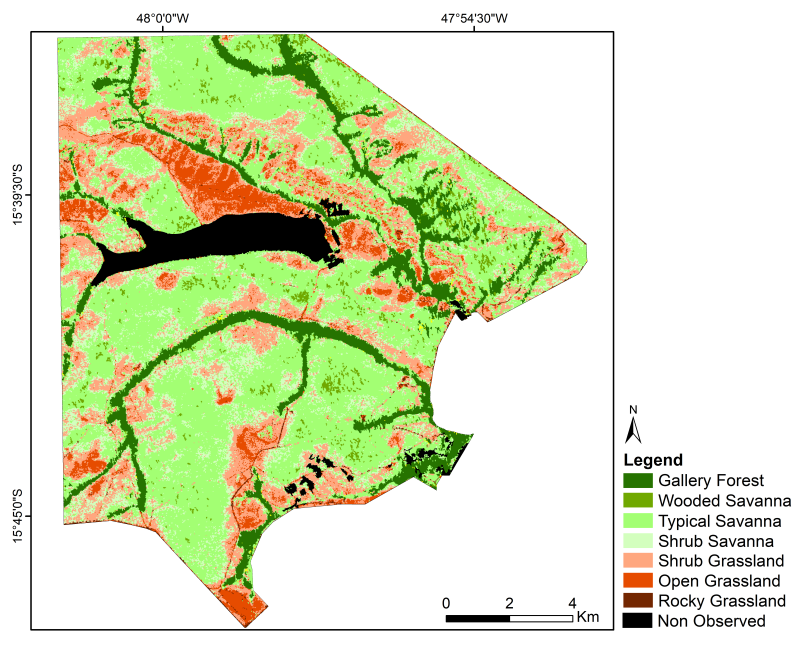

Fig. 1. Vegetation map using hierarchical classification.

with other works that also classified Cerrado physiognomies. Shrub Grassland and Typical Savanna had higher accuracies than [4]. Moreover, Gallery Forest, Typical Savanna, Shrub Grassland and Open Grassland had better accuracies than [3]. Both works were realized on the same study area.

\section{CONCLUSION}

The inclusion of a hierarchical approach has the potential to improve the methodologies for mapping the Cerrado physiognomies. In addition, GEOBIA techniques and Superpixel play an important role in representing the context that characterizes Cerrado physiognomies. Results also showed that some features better characterize some physiognomies than others. Texture features were essential for the First and the Second Level of classification and vegetation indexes were useful for the discrimination of Grasslands physiognomies.

For future works, it is recommended to test more recent classification techniques, such as deep learning. Classifying Cerrado physiognomies is not a trivial task due to the spectral similarity between their vegetation types. Better classification results can reflect on more accurate products, such as the estimation of Carbon storage and biodiversity assessment.

\section{REFERENCES}

[1] R. A. Mittermeier, W. R. Turner, F. W. Larsen, T. M. Brooks, and C. Gascon, "Global biodiversity conservation: the critical role of hotspots," in Biodiversity hotspots, pp. 3-22. Springer, 2011.

[2] J. F. Ribeiro and B. M. T. Walter, "As principais fitofisionomias do bioma cerrado," Embrapa CerradosCapítulo em livro científico (ALICE), 2008.
[3] M. Schwieder, P. J. Leitão, M. M. da Cunha Bustamante, L. G. Ferreira, A. Rabe, and P. Hostert, "Mapping brazilian savanna vegetation gradients with landsat time series," International Journal of Applied Earth Observation and Geoinformation, vol. 52, pp. 361-370, 2016.

[4] C. D. Girolamo Neto, Identification of Brazilian Savanna physiognomies on Brasília National Park using Random Forest on high and medium spatial resolution images, Ph.D. thesis, National Institute for Space Research, 2018.

[5] T. Blaschke, "Object based image analysis for remote sensing," ISPRS journal of photogrammetry and remote sensing, vol. 65, no. 1, pp. 2-16, 2010.

[6] C. Çı̆̆la and A. A. Alatan, "Efficient graph-based image segmentation via speeded-up turbo pixels," in Image Processing (ICIP), 2010 17th IEEE International Conference on. IEEE, 2010, pp. 3013-3016.

[7] T. Perkins, S. Adler-Golden, M. Matthew, A. Berk, G. Anderson, J. Gardner, and G. Felde, "Retrieval of atmospheric properties from hyper and multispectral imagery with the flaash atmospheric correction algorithm," in Remote Sensing of Clouds and the Atmosphere X. International Society for Optics and Photonics, 2005, vol. 5979, p. 59790E.

[8] R. Achanta, A. Shaji, K. Smith, A. Lucchi, P. Fua, and S. Ssstrunk, "Slic superpixels compared to state-of-theart superpixel methods," IEEE Transactions on Pattern Analysis and Machine Intelligence, vol. 34, no. 11, pp. 2274-2282, Nov 2012.

[9] J. Macqueen, "Some methods for classification and analysis of multivariate observations," in In 5-th Berkeley Symposium on Mathematical Statistics and Probability, 1967, pp. 281-297.

[10] R. M. Haralick, K. Shanmugam, et al., "Textural features for image classification," IEEE Transactions on systems, man, and cybernetics, , no. 6, pp. 610-621, 1973.

[11] L. D. Yarbrough, K. Navulur, and R. Ravi, "Presentation of the kauth-thomas transform for worldview-2 reflectance data," Remote Sensing Letters, vol. 5, no. 2, pp. 131-138, 2014.

[12] Y. E. Shimabukuro and J. A. Smith, "The least-squares mixing models to generate fraction images derived from remote sensing multispectral data," IEEE Transactions on Geoscience and Remote sensing, vol. 29, no. 1, pp. 16-20, 1991.

[13] L. Breiman, "Random forests," Machine learning, vol. 45, no. 1, pp. 5-32, 2001. 